\title{
Teor de clorofila e produtividade do jambu sob cultivo hidropônico e solo em diferentes períodos
}

O jambu (Spilanthes oleracea L.) é uma planta da família Asteraceae, nativa da região amazônica, bastante cultivada e consumida na região Norte do Brasil, principalmente no Pará. Tradicionalmente essa hortaliça é cultivada no solo, porém passou a ser cultivada também em sistemas hidropônicos para suprir a sua demanda o ano inteiro. Com isso, o objetivo deste trabalho foi avaliar o teor de clorofila e produtividade do Jambu (cv. Jambuarana) no cultivo hidropônico e cultivo no solo nos períodos chuvoso e seco em Paragominas, Pará. O experimento foi realizado na Universidade Federal Rural da Amazônia, Campus Paragominas e na empresa de hortaliças hidropônicas - B\&A Hidroponia e na Colônia do Uraim com o cultivo em solo, sendo desenvolvido em dois períodos do ano. O delineamento utilizado foi o inteiramente casualisado em esquema fatorial $2 \times 2$, sendo dois sistemas e dois períodos, com cinco repetições. Foram avaliados os parâmetros: número de folhas, peso de massa fresca e área foliar (largura, comprimento, perímetro, proporção e fator de forma) para clorofila foi utilizado o aparelho ClorofiLOGCFL1030. Os mesmos procedimentos foram feitos para o período seco, no mês de setembro. Os dados obtidos foram submetidos à análise de variância, e as médias comparadas pelo teste de Tukey a $5 \%$ de probabilidade. Para sistema dentro do período, as médias de clorofila A, B e Total foram maiores para o sistema solo nos dois períodos do ano. O sistema hidropônico apresentou maior quantidade de clorofila B no período seco. O número de folhas no período seco obteve maior média para o hidropônico. O solo teve maior número de folhas no período chuvoso e o hidropônico no período seco. O mesmo aconteceu para o parâmetro peso de massa fresca. Para área foliar, o sistema hidropônico obteve maior média em relação ao solo nos dois períodos, sendo este com melhor média no período seco. O jambu hidropônico apresentou maior produtividade de g planta-1 em relação ao solo para ambos os períodos, destacandose no periodo chuvoso teve o sistema hidropônico com maior média. Para perímetro a hidroponia foi melhor nos dois períodos em relação ao solo, onde o período seco obteve maior perímetro foliar. Para Fator de Forma no período chuvoso o solo destacou-se. A Clorofila foi melhor no solo.

Palavras-chave: Spilanthes oleracea L.; Hortaliça; Jambuarana; Cultivo hidropônico; Cultivo no solo.

\section{Chlorophyl content and productivity of jambu under hydroponic cultivation and soil in different periods}

Jambu (Spilanthes oleracea L.) is a plant from the Asteraceae family, native of the Amazon region, and widely cultivated and eaten in the north of Brazil, mainly in the Pará State. Traditionally, Jambu (Spilanthes oleracea L.) is a plant from the Asteraceae family, native of the Amazon region, and widely cultivated and eaten in the north of Brazil, mainly in the Para State. Traditionally, (cv. Jambuarana) in hydroponic cultivation and cultivation in the soil in the rainy and dry periods in Paragominas, Pará. The experiment was conducted at the Federal Rural University of (cv. Jambuarana) in hydroponic cultivation and cultivation in the soil in the rainy and dry periods in Paragominas, Para. The experiment was conducted at the Federal Rural University of the year. The experimental design was completely randomized in a $2 \times 2$ factorial scheme, being two systems and two periods with five repetitions. The parameters were evaluated: a number of leaves, the weight of the fresh mass, and leaf area (width, length, perimeter, ratio fac, and shape fac) the chlorophyll, the instrument ClorofiLOG-CFL1030. The data obtained was subjected to the analysis of variance, and the averages were compared using the Tukey test at $5 \%$ of probability. For the system within the period, the mean chlorophyll a, b, and total were higher for the soil system in the two periods of the year. The hydroponic system showed a higher amount of chlorophyll $b$ in the dry season. The number of leaves in the dry season had the highes meanto the hydroponics. The soil had the highest number of leaves in the rany season and the hydroponic, in the dry season. The same happened for the parameter weight of the fresh

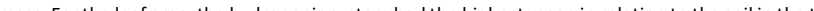
作 soil in the dry period and the length in the two periods. For the ratio fac, the rainy season had the highest mean in the hydroponic system. For the shape facing the rainy season, the soil stood out in this period with the highest mean. The chlorophyll was better in soil.

Keywords: Spilanthes oleracea L.; Vegetable; Jambuarana; Hydroponic Cultivation; Soil Cultivation.

Ivy Freitas Silva (iD

Universidade Federal Rural da Amazônia, Brasil http://lattes.cnpq.br/3022744702002230

http://orcid.org/0000-0001-7185-9400

ivyfreiitas@gmail.com

Rhaniely Dairys Lima Silva (iD

Universidade Federal Rural da Amazônia, Brasil http://lattes.cnpq.br/1033336459038819

http://orcid.org/0000-0001-6829-0452

rhanielydairys.agro@hotmail.com

Luciana da Silva Borges (iD

Universidade Federal Rural da Amazônia, Brasil http://lattes.cnpq.br/4533722536181534

http://orcid.org/0000-0002-1194-6411

luciana.borges@ufra.edu.br
Luana Keslley Nascimento Casais (iD

Universidade Federal Rural da Amazônia, Brasil http://lattes.cnpq.br/8075409193627849

http://orcid.org/0000-0001-7197-5524

luana.casais@gmail.com

Michelane Silva Santos Lima

Universidade Estadual Paulista Júlio Mesquita Filho, Brasil http://lattes.cnpq.br/6818368804286499

http://orcid.org/0000-0002-5844-5833

michelanesilva12@gmail.com

Kelly de Nazaré Maia Nunes (ic

Universidade Federal Rural da Amazônia, Brasil

http://lattes.cnpq.br/3896224482356725

http://orcid.org/0000-0002-5036-7308

kelly mnunes@hotmail.com
Alberto de Sousa Pereira Junior (iD

Universidade Federal Rural da Amazônia, Brasi http://lattes.cnpq.br/1209629388824815 http://orcid.org/0000-0002-2002-315X albertopereirajr@gmail.com

Maria do Bom Conselho Lacerda Medeiros (ii) Universidade Federal Rural da Amazônia, Brasil http://lattes.cnpq.br/4581189119190265

http://orcid.org/0000-0002-1364-6877 melmedeirosagro@gmail.com 


\section{INTRODUÇÃO}

O jambu (Spilanthes oleracea L.) é uma planta da família Asteraceae, nativa da região amazônica, hortaliça herbácea perene, semiereta e de ramos decumbentes. As inflorescências são amareladas e dispostas em capítulos (MARTINS et al., 2012). Essa planta é uma hortaliça bastante cultivada e consumida na região Norte do Brasil, principalmente no Pará, sendo sua maior demanda nos períodos festivos, tais como o Círio de Nazaré e as festas de fim de ano (BORGES et al., 2014a). Para Borges et al. (2012) as plantas de jambu, tem efeito farmacológico. Pois, segundo Borges et al. (2014b), essa planta, apresenta propriedades químicas, o que vem despertando o interesse das empresas. Borges et al. (2015a) constaram que as plantas de jambu possuem teores de flavonoides e vitamina C em suas folhas. Segundo Borges et al. (2019), essa alta concentração no teor de antioxidante, tem despertando o interesse de empresas de cosméticos.

Popularmente também é utilizada como erva medicinal, pois segundo os dizeres populares suas folhas e flores podem ser recomendadas para elaboração de infusões no tratamento de anemia, dor de dente e garganta, sendo sugerido como antibiótico e anestésico. Apesar dessas novidades, a hortaliça continua invisível nas estatísticas de produção e de mercado no Pará (BORGES et al., 2012). Isso ocorre tanto no sistema de cultivo em solo como em sistema de cultivo hidropônico.

Para o sistema de cultivo no solo, o jambu exige solos bem drenados, leves, férteis e ricos em matéria orgânica (MAPA, 2010). Os solos para o cultivo dessa hortaliça devem ser os argilo-arenosos e ricos em matéria orgânica. Solos de várzea, quando bem drenados também podem ser utilizados para o cultivo (POLTRONIERI et al., 1998). Tolera solos ácidos (VILLACHICA, 1996). Essa forma de cultivo já vem sendo utilizada durante muitos anos, no entanto, o uso intensivo do solo pode causar problemas como infertilidade, perda de nutrientes, além da compactação, o que acaba impossibilitando a obtenção de produtos de boa qualidade através desse sistema convencional. Tradicionalmente cultivado no solo, o jambu também passou a ser cultivado em sistemas hidropônicos, o qual se encontra em crescimento no estado.

A hidroponia é um sistema de cultivo em que as plantas são capazes de se desenvolver plenamente sem a utilização do solo. Neste sistema de cultivo, as plantas se desenvolvem e são alimentadas por meio de uma solução nutritiva, ou seja, em água onde são dissolvidos os sais contendo todos os nutrientes essenciais à sua sobrevivência e desenvolvimento (ALMEIDA, 2016).

O plantio do jambu em hidroponia com Técnica do Fluxo Laminar de Nutrientes (NFT) apresenta uma alternativa para esse sistema, assim como o cultivo da alface, demanda constante durante o ano, e como produto diferenciado para os consumidores (HOMMA et al., 2011). Os cultivos hidropônicos possibilitam a obtenção de produtos de boa qualidade quando comparados aos sistemas convencionais, devido à maior uniformidade na colheita e eficiência no uso da água para fins de irrigação (FAQUIN et al., 1996). Possibilitando também a produção na Região Norte tanto em período seco quanto em período chuvoso.

$\mathrm{Na}$ região, os meses de junho a novembro apresentam um período seco, com baixos índices pluviométricos, já o restante do ano caracteriza-se por um período chuvoso muito intenso, o que prejudica a produção do jambu. Sabe-se que o clima é um fator que influencia bastante a produção de hortaliças. Em 
algumas regiões no verão, a alta pluviosidade e alta temperatura interferem na qualidade e produção das hortaliças e criam condições favoráveis para o aparecimento de doenças (GOTO et al., 1998).

O período chuvoso no sistema de produção em solo provoca diminuição na produção, e a hidroponia vem como uma alternativa para se produzir o ano inteiro. Diante disso, sabendo-se que a demanda do jambu é maior em alguns meses do ano, principalmente em períodos festivos, e é extremamente reduzida nos outros períodos, estudos mostram que as condições climáticas podem estar muito atreladas a este efeito na produção. Com isso, utiliza-se a técnica da hidroponia que ajuda aumentar a sua produção, suprindo a demanda o ano inteiro. Desta forma, objetivou-se avaliar o teor de clorofila e produtividade do Jambu (cv. Jambuarana) no cultivo hidropônico e cultivo no solo nos períodos chuvoso e seco em Paragominas, Pará.

\section{MATERIAIS E MÉTODOS}

O experimento foi realizado nos bairros Condomínio Rural e Colônia do Uraim, na cidade de Paragominas, no estado do Pará, coordenadas 02 59' 45" latitude Sul e 470 21' 10" longitude Oeste. O clima da microrregião de Paragominas pode ser caracterizado por apresentar condições gerais de clima quente e úmido, enquadrando-se nos tipos climáticos Awi da classificação de Koppen e B1wA'a', da classificação de Thonthwaite. A média anual de temperatura é $26,3{ }^{\circ} \mathrm{C}$ e varia durante os meses entre $25,6{ }^{\circ} \mathrm{C}$ (fevereiro e julho) e $27,0^{\circ} \mathrm{C}$ (outubro e novembro) (BASTOS et al., 2005).

O delineamento utilizado foi o inteiramente casualisado (DIC) em esquema fatorial $2 \times 2$, sendo dois sistemas de cultivo (solo e hidropônico) e dois períodos (chuvoso e seco), com cinco repetições. As coletas de dados foram feitas em dois períodos do ano, estação chuvosa e seca, sendo considerado período chuvoso os meses de fevereiro a maio e período seco de julho a novembro, nos sistemas de cultivo de Jambu (cv. Jambuarana) no solo e na hidroponia.

A primeira coleta foi realizada no período chuvoso, mês de Abril, apresentando temperatura média de $26,8^{\circ} \mathrm{C}$ (INMET, 2018), sendo o jambu hidropônico coletado no bairro Condomínio Rural, na propriedade da empresa B\&A hidroponia. O cultivo é feito em bancadas medindo 7 metros $(\mathrm{m})$ de comprimento por 1,70 $\mathrm{m}$ de altura, declividade a 5\%, tendo os furos das bancadas espaçados em $24 \mathrm{~cm}$ entre plantas e $24 \mathrm{~cm}$ entre bancadas, com arranjo de plantas em triângulo. $O$ jambu foi semeado no dia 03 de março e transferido para as bancadas 20 dias depois da semeadura.

Ainda nas bancadas, a determinação dos teores de clorofila A, B e Total foi feita com o aparelho ClorofiLOG-CFL1030, onde foram medidas 3 folhas por planta (folhas totalmente expandidas), um ponto em cada folha, em 8 plantas e em seguida, foram colhidas um total de 15 plantas, colocadas em sacos plásticos e identificadas por número de 1 a 15. A solução nutritiva do sistema estava com pH 7.8 e condutividade $1.1 \mu \mathrm{S} / \mathrm{cm}$. O jambu cultivado no solo foi coletado no bairro Colônia do Uraim, na propriedade do Sr. João Leandro, em canteiro medindo $15 \mathrm{~m}$ comprimento por 1,5m de largura, coberto com plástico transparente e estrutura de madeira, com pé direito de aproximadamente $2 \mathrm{~m}$.

A muda de jambu foi feita no próprio canteiro de cultivo, em um espaço pequeno chamado de canteiro berçário, onde passa 30 dias, e em seguida é transplantada para o canteiro definitivo, onde 
permanecem até a colheita. Com o aparelho medidor de clorofila foi feita medição ainda no solo, da mesma forma feita no jambu hidropônico, em seguida foram colhidas um total de 15 plantas, colocadas em sacos plásticos e identificadas com numeração de 1 a 15.

No solo de cultivo o proprietário havia feito calagem e realizado adubação, utilizando de adubo orgânico o esterco de galinha e esterco bovino curtido e como adubação mineral foi aplicada ureia. Além disso, o produtor realizava irrigação por microaspersão, duas vezes ao dia, utilizando mangueiras Santeno. Logo após as coletas em campo, as plantas de jambu foram levadas nos sacos plásticos para o laboratório multifuncional da Universidade Federal Rural da Amazônia (UFRA), campus Paragominas, onde foram realizadas as análises dos parâmetros: número de folhas, peso de massa fresca e área foliar. 0 primeiro parâmetro analisado foi o número de folhas, onde foram contadas todas as folhas, desde as mais jovens, de cada planta de jambu cultivadas no solo e na hidroponia.

Em seguida as raízes de cada planta foram cortadas, descartadas, e posteriormente, com o auxílio de uma balança de precisão, as plantas foram pesadas individualmente para obtenção do peso de massa fresca. Para o parâmetro área foliar, com o auxílio do aparelho Área Meter AM 350, foram medidas 5 folhas por planta (folhas velhas de tamanhos semelhantes), onde foram feitas 5 repetições, utilizando duas plantas por repetição, totalizando 10 plantas. Além da área foliar o aparelho informa dados como perímetro, largura, comprimento da folha, fator de forma e proporção.

A segunda coleta foi realizada no período seco, no mês de setembro, com temperatura média de $28^{\circ} \mathrm{C}$ (INMET, 2018), sendo feitas nas mesmas propriedades em que foram realizadas as primeiras coletas, tanto do cultivo de jambu no solo quanto o hidropônico. Nesse período o produtor do jambu cultivado no solo realizou no canteiro a calagem, a mesma adubação orgânica e mineral do período chuvoso, com o manejo de irrigação por microaspersão através de mangueiras Santeno, duas vezes ao dia. Foi observada maior incidência de plantas daninhas no canteiro nesse período, como caruru, burra-leiteira e serralha.

Ainda no canteiro foram feitas as medições com o aparelho medidor de clorofila, em 8 plantas, 3 folhas por planta, um ponto em cada folha. Em seguida foram retiradas o total de 15 plantas, colocadas em sacos plásticos e identificadas. Na hidroponia, o jambu havia sido semeado no dia 15 de julho e vinte dias depois do plantio, transferidas para as bancadas. Ainda nas bancadas foi realizada a coleta dos dados de clorofila da mesma forma que foi feita no cultivo no solo, em seguida colhidas 15 plantas. A solução nutritiva estava com pH 6 e a condutividade $1.2 \mu \mathrm{S} / \mathrm{cm}$.

Após as coletas, as plantas de jambu dos sistemas de cultivo solo e hidropônico foram levadas ao laboratório da UFRA onde foram realizadas as análises dos parâmetros número de folha, peso de massa fresca e área foliar (comprimento, largura, perímetro, proporção e fator de forma), da mesma maneira realizada no primeiro período analisado.

Ao final a produtividade foi calculada através do produto do peso de massa fresca pelo número de plantas coletadas (g.planta $\left.{ }^{-1}\right)$. Os dados obtidos nesse estudo foram submetidos à análise de variância, e as médias comparadas pelo teste de Tukey a 5\% de probabilidade, sendo as análises estatísticas realizadas com o software SISVAR (FERREIRA, 2000). 


\section{RESULTADOS E DISCUSSÃO}

De acordo com a Tabela 1, verifica-se interação significativa para o sistema (solo e hidroponia) e período (chuvoso e seco) para número de folhas, peso de massa fresca, área foliar e produtividade, assim como houve efeito significativo para o sistema em todos os parâmetros, no entanto, para o período houve efeito significativo apenas para o número de folhas. Diante disso foi realizado o desdobramento para verificar qual fator interferiu no resultado, sistema ou período.

As médias do número de folhas das plantas de jambu não diferiram entre si no desdobramento de sistemas dentro do período, para o período chuvoso, já para o período seco a hidroponia apresentou maior média de número de folhas (Tabela 1). No desdobramento de período dentro de cada sistema, no sistema de cultivo solo, as médias foram maiores no período chuvoso, e para a hidroponia o número de folhas foi melhor no período seco (Tabela 1). De acordo com Streck et al. (2003), a taxa de emissão do número de folhas de algumas espécies é afetada pelo fotoperíodo.

No estudo realizado em Minas Gerais por Honório et al. (2009) com o jambu cultivado no solo, o número de folhas variou entre as épocas de plantio, com uma tendência de aumento no período do verão, onde se coincidem temperaturas mais elevadas $\left(24,7^{\circ} \mathrm{C}\right)$. Neste trabalho também ocorreu variação entre as épocas de plantio, no entanto o jambu do solo apresentou maior número de folhas no período chuvoso, porém a temperatura média nesta época no ano foi superior à temperatura do período do verão do estudo citado $\left(26,8^{\circ} \mathrm{C}\right)$. Essa diferença no número de folhas entre os períodos para o jambu no solo pode ter sido influenciada também pelo manejo empregado pelo produtor no período seco, pois foi verificada uma maior incidência de plantas daninhas no canteiro neste período do que no período chuvoso.

Tabela 1: Médias dos parâmetros analisados nos sistemas de cultivo do jambu em dois períodos do ano.

\begin{tabular}{lllll}
\hline Sistema & $\mathrm{N}^{\circ}$ de folhas & Peso $(\mathrm{g})$ & Área foliar $\left(\mathrm{mm}^{2}\right)$ & Produtividade (g.planta-1) \\
\hline Período chuvoso & & & & \\
\hline Solo & $215,60 \mathrm{aA}$ & $146,40 \mathrm{bA}$ & $2614,42 \mathrm{bA}$ & $439,20 \mathrm{bA}$ \\
Hidroponia & $279,66 \mathrm{aB}$ & $247,68 \mathrm{aB}$ & $4314,24 \mathrm{aB}$ & $743,06 \mathrm{aB}$ \\
\hline Período seco & & & & \\
\hline Solo & $97,53 \mathrm{bB}$ & $59,46 \mathrm{bB}$ & $2396,92 \mathrm{bA}$ & $178,40 \mathrm{bB}$ \\
Hidroponia & $791,860 \mathrm{aA}$ & $300,53 \mathrm{aA}$ & $4775,84 \mathrm{aA}$ & $901,61 \mathrm{aA}$ \\
\hline Sistema & $* *$ & $* *$ & $* *$ & $* *$ \\
Período & $* *$ & $\mathrm{NS}$ & $\mathrm{NS}$ & $\mathrm{NS}$ \\
SistemaxPeríodo & $* *$ & $* *$ & $* *$ & $* *$ \\
\hline CV \% & 19,15 & 14,98 & 8,29 & 14,98 \\
\hline
\end{tabular}

* Letras minúsculas comparam médias do sistema dentro do período. Letras maiúsculas comparam médias do período dentro de cada sistema. Médias seguidas das mesmas letras na coluna não diferem entre si pelo Teste de Tukey a $5 \%$ de probabilidade.

Para o parâmetro peso, as médias diferiram entre si no desdobramento de sistema dentro do período, nos dois períodos analisados, sendo o sistema hidropônico melhor em relação ao solo em ambos (Tabela 1). No trabalho realizado por Farias et al. (2011), plantas cultivadas em hidroponia apresentaram valores superiores estatisticamente significativos em todas as características avaliadas quando comparadas às plantas cultivadas em solo. Porém, existem poucos trabalhos e uma insuficiente diversidade de dados que possam caracterizar e diferenciar os tipos de cultivo do jambu.

No desdobramento de período dentro de cada sistema, no sistema solo as médias de peso das 
plantas de jambu foram maiores no período chuvoso, já para o sistema hidropônico as médias de peso foram maiores no período seco do ano (Tabela 1), o que pode ser justificado devido ao número de folhas terem sido maior para os sistemas nesses respectivos períodos, como foi citado anteriormente. Constatou-se para a área foliar que no desdobramento de sistema dentro do período as médias diferiram entre si nos dois períodos, sendo a hidroponia com maiores médias de área foliar para ambos (Tabela 1).

No desdobramento de período dentro de cada sistema, o sistema solo não diferiu nos períodos, já a hidroponia apresentou melhores resultados no período seco, $4.775,84 \mathrm{~mm}^{2}$ de área foliar (Tabela 1). Borges et al. (2010) obtiveram médias de 1.527,64 cm² de área foliar em plantas de jambu (cv. Jambuarana), valor esse acima do encontrado neste trabalho. Segundo Taiz et al. (2013) a área foliar tem sua importância por ser uma variável de crescimento indicativa da produtividade, visto que o processo fotossintético depende da interceptação da energia luminosa e sua conversão em energia química, sendo este um processo que ocorre diretamente na folha.

Para a produtividade no desdobramento de sistema dentro do período houve diferença significativa de médias para ambos os períodos, sendo o jambu de sistema hidropônico com melhor média de produtividade tanto no período chuvoso quanto no período seco (Tabela 1). Analisando o período em cada sistema, o sistema de cultivo no solo apresentou efeito significativo superior com 439,20 g.planta-1 no período chuvoso, já no cultivo hidropônico o melhor resultado de produtividade foi no período seco de 901,61 g,planta-1 (Tabela 1). Segundo Borges et al. (2013) o jambu tem uma produtividade de 3,37 kg.m-2.

Verifica-se na Tabela 2 que não houve interação significativa entre os sistemas (solo e hidroponia) e os períodos (chuvoso e seco) para clorofila a, b e total, assim como para o período na clorofila a. No entanto, ocorreu efeito significativo no período para clorofila b e total, assim como para os sistemas na clorofila a, b e total.

Diante disso, verifica-se que o solo apresentou o melhor resultado de clorofila A, B e Total, tanto no período seco como no chuvoso (Tabela 2). Provavelmente, este resultado tenha sido influenciado pelo manejo de adubação realizado pelo produtor de jambu no solo, onde se utiliza esterco bovino e de ave como fonte de adubação, ricos em nutrientes, principalmente o nitrogênio, além da adubação com ureia. Já no sistema hidropônico ainda não há uma formulação específica de solução nutritiva para o jambu, fazendo com que a planta sinta os efeitos nutricionalmente. Segundo Shadchina et al. (1995) o teor de clorofila da folha também se correlaciona com o teor de $\mathrm{N}$ na planta.

No desdobramento de período dentro de cada sistema, as médias diferiram apenas para a clorofila B, onde o sistema hidropônico apresentou melhor resultado somente para o período seco (Tabela 2). Na Tabela 3 observa-se que houve interação significativa para o sistema (solo e hidroponia) e período (chuvoso e seco) apenas nos parâmetros proporção de folha, perímetro e fator de forma, para o período houve efeito significativo apenas para o parâmetro perímetro e para sistema houve efeito significativo para todos os parâmetros, exceto para a proporção. 
Tabela 2: Médias de clorofila de plantas de jambu em sistemas de cultivo no período chuvoso e seco do ano, em Paragominas/PA.

\begin{tabular}{|c|c|c|c|}
\hline \multirow{2}{*}{ Sistema } & \multicolumn{3}{|c|}{ Clorofila } \\
\hline & Clorofila A & Clorofila B & Clorofila Total \\
\hline \multicolumn{4}{|l|}{ Período chuvoso } \\
\hline Solo & $31,02 \mathrm{aA}$ & 10,06 aA & 41,36 aA \\
\hline Hidroponia & 27,58 bA & $7,20 \mathrm{bB}$ & $34,23 \mathrm{bA}$ \\
\hline \multicolumn{4}{|l|}{ Período seco } \\
\hline Solo & $32,24 \mathrm{aA}$ & 10,55 aA & 44,57 aA \\
\hline Hidroponia & $28,78 \mathrm{bA}$ & $8,47 \mathrm{bA}$ & $37,23 \mathrm{bA}$ \\
\hline Sistema & $* *$ & $* *$ & $* *$ \\
\hline Período & NS & $* *$ & $* *$ \\
\hline SistemaxPeríodo & NS & NS & NS \\
\hline CV \% & 4,17 & 7,04 & 5,71 \\
\hline
\end{tabular}

* Letras minúsculas comparam médias do sistema dentro do período. Letras maiúsculas comparam médias do período dentro de cada sistema. Médias seguidas das mesmas letras na coluna não diferem entre si pelo Teste de Tukey a $5 \%$ de probabilidade.

O parâmetro largura no desdobramento de sistema dentro do período as médias diferiram entre si apenas no período seco, onde a hidroponia se sobressaiu sob o sistema solo (Tabela 3). No parâmetro comprimento as médias diferiram entre si no desdobramento de sistemas dentro do período, tanto no período chuvoso quanto no período seco, sendo o sistema hidropônico com maiores médias em ambos (Tabela 3).

Tabela 3: Médias dos parâmetros analisados nos sistemas de cultivo do jambu em dois períodos do ano.

\begin{tabular}{llllll}
\hline Sistema & Largura $(\mathrm{mm})$ & Comprimento $(\mathrm{mm})$ & Proporção & Perímetro $(\mathrm{mm})$ & Fator de forma \\
\hline Período chuvoso & & & & & \\
\hline Solo & $57,71 \mathrm{aA}$ & $70,97 \mathrm{bA}$ & $1,23 \mathrm{bA}$ & $255,04 \mathrm{bA}$ & $0,506 \mathrm{aA}$ \\
Hidroponia & $64,97 \mathrm{aA}$ & $89,43 \mathrm{aA}$ & $1,51 \mathrm{aA}$ & $831,76 \mathrm{aA}$ & $0,131 \mathrm{bB}$ \\
\hline Período seco & & & & & \\
\hline Solo & $51,56 \mathrm{bA}$ & $70,14 \mathrm{bA}$ & $1,36 \mathrm{aA}$ & $330,16 \mathrm{bA}$ & $0,311 \mathrm{aB}$ \\
Hidroponia & $72,54 \mathrm{aA}$ & $86,83 \mathrm{aA}$ & $1,21 \mathrm{aB}$ & $531,70 \mathrm{aB}$ & $0,269 \mathrm{aA}$ \\
\hline Sistema & $* *$ & $* *$ & $\mathrm{NS}$ & $* *$ & $* *$ \\
Período & $\mathrm{NS}$ & $\mathrm{NS}$ & $\mathrm{NS}$ & $* *$ & $\mathrm{NS}$ \\
SistemaxPeríodo & $\mathrm{NS}$ & $\mathrm{NS}$ & $* *$ & $* *$ & $* *$ \\
\hline CV \% & 11,92 & 4,88 & 12,68 & 14,30 & 24,58 \\
\hline
\end{tabular}

* Letras minúsculas comparam médias do sistema dentro do período. Letras maiúsculas comparam médias do período dentro de cada sistema. Médias seguidas das mesmas letras na coluna não diferem entre si pelo Teste de Tukey a $5 \%$ de probabilidade.

No parâmetro proporção de folha as médias no desdobramento de sistemas dentro do período diferiram entre si apenas para o período chuvoso, sendo o sistema hidropônico com maior média. No desdobramento de período dentro de cada sistema, no sistema solo as médias não diferiram entre si nos dois períodos, já o sistema hidropônico apresentou melhores médias no período chuvoso (Tabela 3).

Para o perímetro, ao analisar os sistemas dentro do período, as médias diferiram entre si para os dois períodos, onde o sistema hidropônico foi melhor tanto no período chuvoso quanto no período seco em relação ao sistema solo. Para o desdobramento de período dentro de cada sistema, as médias do sistema solo não diferiram entre si, já as médias do sistema hidropônico diferiram entre si, sendo o perímetro das folhas maior no período chuvoso (Tabela 3).

Para o parâmetro fator de forma, no desdobramento de sistemas dentro do período as médias diferiram entre si apenas no período chuvoso, onde o solo se destacou em relação à hidroponia. No 
desdobramento de período dentro de cada sistema, o sistema solo obteve maiores médias no período chuvoso e a hidroponia no período seco (Tabela 3).

\section{CONCLUSÕES}

A produtividade de jambu apresenta melhor resultado no sistema hidropônico, cultivado no período seco. Cultivando o jambu no solo, o melhor resultado de produtividade será no período chuvoso. O jambu hidropônico apresentou melhores resultados, quando comparado ao sistema de cultivo no solo, em maior parte dos parâmetros analisados. A clorofila ( $a$, b e total) no sistema solo foi superior ao sistema hidropônico no período chuvoso e seco. Embora existam literaturas sobre o cultivo dessa hortaliça, ainda há uma insuficiência de dados sobre os sistemas de cultivo, principalmente para o sistema hidropônico.

\section{REFERÊNCIAS}

ALMEIDA, P. C.. Diferentes métodos de cultivo hidropônicos e seus manejos. In: ENCONTRO, 11; E SIMPÓSIO BRASILEIRO DE HIDROPONIA, 3. Anais. Florianópolis, 2016.

BASTOS, T. X.; PACHÊCO, N. A.; FIGUEIREDO R. O.; SILVA, G. F. G.. Características Agroclimáticas do Município de Paragominas. Belém: Embrapa Amazônia Oriental, 2005.

BORGES, L. S.; AVIZ, R. O.; CASAIS, L. K. N.; VASCONCELOS, E. S.. JAMBU-Hortaliça Amazônica tem demanda garantida. Campo \& negócios, v.165, p.26-27, 2019.

BORGES, L. S.; GOTO, R.; NUNES, K. N. M.; VIANELLO, F.; LIMA, G. P. P.. Concentração Das Atividades Antioxidantes Em Plantas De Jambu, Cultivadas Sob Adubação Orgânica E Mineral. Enciclopédia Biosfera, Centro Científico Conhecer, Goiânia, v.11, n.22, p.2015.

BORGES, L. S.; GOTO, R.; LIMA, G. P. P.. Índices morfofisiológicos e produtividade de cultivares de jambu influenciadas pela adubação orgânica e mineral. Biosci. J., Uberlândia, v.30, n.6, p.1768-1778, 2014a.

BORGES, L. S.; NUNES, K. N. M.; JACQUES, R. A.; LIMA, G. P. P.. Perfil cromatográfico do óleo essencial de jambu identificados por cromatógrafo a gás acoplado a espectrômetro de massas. Cultivando o Saber, v.7, n.3, p.254-266, 2014b.

BORGES, L. S.; GOTO, R.; LIMA, G. P. P.. Produtividade e acúmulo de nutrientes em plantas de jambu, sob adubação orgânica e mineral. Semina: Ciências Agrárias, Londrina, v.34, n.1, p.83-94, 2013.

BORGES, L. S.. Potencial antioxidante, Óleo essencial e atividade antifúngica de plantas de jambu (spilanthes oleracea), cultivadas sob adubação orgânica e convencional: Processamento mínimo de nectarina (prunus persica var. nectarina): conservação de suas qualidades e propriedades bioativas. Tese (Doutorado em Agronômicas) Universidade Estadual Paulista "Júlio de Mesquita Filho", Botucatu, 2012.

BORGES, L. S.; GOTO, R.; LIMA, G. P. P.. Comparação de cultivares de jambu influenciada pela adubação orgânica. Horticultura Brasileira, v.30, p.S2261-S2267, 2012.
BORGES, L. S.; GUERRERO, A. C.; FERNANDES, D. M.. Adubação foliar com silício no crescimento de plantas de jambu. Cultivando o Saber, Cascavel, v.3, n.1, p.160-170, 2010.

FAQUIN, V.; FURTINI NETO, A. E.; VILELA, L. A. A.. Produção de alface em hidroponia. Lavras: UFLA, 1996.

FARIAS, V. D. S.; SOUZA, G. T.; GUSMÃO, A. L.; SAMPAIO, I. M. G.; CASTRO, L. N.. Teores de minerais em diferentes variedades de jambu conduzidas em solo e hidroponia NFT em Belém-Pará. Horticultura Brasileira, v.29, n.2, p.S1658S1664, 2011.

FERREIRA, D. F.. Análises estatísticas por meio do Sisvar para Windows versão 4.0. In: REUNIÃO ANUAL DA REGIÃO BRASILEIRA DA SOCIEDADE INTERNACIONAL DE BIOMETRIA, 45. Anais. São Carlos: UFSCar, 2000. p.255-258.

GOTO, R.; TIVELLI, S. W.. Produção de hortaliças em ambiente protegido: condições subtropicais. In: TIVELLI, S. W.. Manejo do ambiente em cultivo protegido. São Paulo: UNESP, p.15-30, 1998.

HOMMA, A. K. O.; SANCHES, R. S.; MENEZES, A. J. E. A.; GUSMÃO, S. A.. Etnocultivo do jambu para Abastecimento da cidade de Belém. Amazônia: Ci. \&Desenv., v.6, n.12, p.141, 2011.

HONÓRIO, I. C. G.; PARREIRAS, N. S.; GOMES, J. A. O.; MELO, M. T. P.; MARTINS, E. R.; COSTA, C. A.. Melhor época de plantio de jambu (Spilanthes oleracea L.). Horticultura Brasileira, v.27, p.S2176-S2181, 2009.

INMET. Instituto Nacional de Meteorologia. Estação Meteorológica de Observação de Superfície Automática: Paragominas/PA. 2018.

MAPA. Ministério da Agricultura, Pecuária e Abastecimento. Manual de Hortaliças não-convencionais. Brasília: MAPA, 2010.

MARTINS, C. P. S.; MELO, M. T. P.; HONÓRIO, I. C. G.; D'ÁVILA, V. A.; CARVALHO JÚNIOR, W. G. O.. Caracterização morfológica e agronômica de acessos de jambu (Spilanthes 
oleracea L.) nas condições do Norte de Minas Gerais. Revista Brasileira de Plantas Medicinais, Botucatu, v.14, p.410-413, 2012.

POlTRONIERI, M. C.; POLTRONIERI, L. S.; MULLER, N. R. M.. Cultivo do jambu (Spilanthes oleracea L.). Manaus: Embrapa Amazônia Oriental, 1998.

SCHADCHINA, T. M.; DMITRIEVA, V. V.. Leaf chlorophyll content as a possible diagnostic mean for the evaluation of plant nitrogen uptake from the soil. Journal of Plant Nutrition, New York, v.18, p.1427-1437, 1995.
STRECK, N. A.; WEISS, A.; XUE, Q.; BAENZIGER, P. S.. Incorporating a chronology response into the prediction of leaf appearance rate in winter wheat. Annals of Botany, Oxford, v.92, n.2, p.181-190. 2003

TAIZ, L.; ZEIGER, E.. Fisiologia vegetal. Porto Alegre: Artmed, 2013.

VILLACHICA, H.. Frutales y hortalizas promisorios de la Amazônia. Lima: Tratado de Cooperacion Amazônica, 1996.

A CBPC - Companhia Brasileira de Produção Científica (CNPJ: 11.221.422/0001-03) detém os direitos materiais desta publicação. Os direitos referem-se à publicação do trabalho em qualquer parte do mundo, incluindo os direitos às renovações, expansões e disseminações da contribuição, bem como outros direitos subsidiários. Todos os trabalhos publicados eletronicamente poderão posteriormente ser publicados em coletâneas impressas sob coordenação da Sustenere Publishing, da Companhia Brasileira de Produção Científica e seus parceiros autorizados. Os (as) autores (as) preservam os direitos autorais, mas não têm permissão para a publicação da contribuição em outro meio, impresso ou digital, em português ou em tradução. 